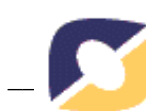

\title{
Mapas de Trocas Intelectuais: representações para cooperação na educação a distância
}

Silvana Corbellini, UFRGS, silvanacorbellini@gmail.com

\author{
Maria Luiza Rheingantz Becker, UFRGS, beckermarialuiza@gmail.com
}

RESUMO: Este artigo apresenta uma pesquisa sobre a cooperação em um curso de especialização a distância em uma universidade federal. O objetivo da pesquisa foi investigar e analisar como os processos individuais e interindividuais possibilitam a ocorrência da cooperação intelectual entre os discentes. Elegeu-se a teoria de Jean Piaget para a fundamentação, a fim de auxiliar na compreensão do método de cooperação. Para responder ao problema da pesquisa registraram-se as sequências de interações entre os participantes do curso, traçando-se rotas e desenhando-se Mapas das Trocas Intelectuais. Estes mapas se mostraram como instrumentos profícuos para auxiliar no entendimento das dificuldades e potencialidades de cada discente, bem como da totalidade dos integrantes do curso. O desenho dos mapas permite que se identifiquem os interesses dos discentes, os temas que os motivam, as dificuldades que possam estar enfrentando e as possibilidades de novos encaminhamentos no processo de ensino e aprendizagem, potencializando aprendizagens ativas, cooperativas e autônomas.

Palavras-chave: Cooperação. Educação a distância. Mapas das Trocas Intelectuais.

\section{Intellectual Exchange Maps: useful tools to promote cooperation in distance education}

\begin{abstract}
The research presented in this article was conducted in a distance education specialization course at a Brazilian federal university. The research objective involved inquiring and analyzing how individual and inter-individual processes allow intellectual cooperation between students, and the theoretical framework chosen was Jean Piaget's genetic epistemology. We mapped the students' interactions, tracing their learning pathways and creating Intellectual Exchange Maps. These maps served as useful tools to understand the difficulties and potentials of not only each student, but of the class as a whole. Following them through the mapping of their learning pathways has allowed us to identify their interests, the topics that motivate them and the difficulties they might be facing, and also to find new procedures in the teaching and learning process.
\end{abstract}

Keywords: Cooperation. Distance education. Intellectual Exchange Maps.

\section{Introdução}

A cooperação tem sido um dos conceitos destacados no discurso sobre a educação. Sua importância no contexto atual tem suscitado reflexões e debates visando 
compreender sua presença e contribuição para os processos de inclusão, de ensino e de aprendizagem. Uma das questões que se mostra pertinente é, no caso deste artigo, como a cooperação se constitui em ambientes de aprendizagem e qual sua importância nesse contexto. Neste caso específico, a abordagem centrou-se na educação na modalidade a distância, responsável pelo aumento da oferta de educação superior, tanto na graduação como em cursos de especialização. Um dos aspectos mais preocupantes é a qualidade desta modalidade de educação, e, com isto, tem-se procurado construir pedagogias interativas, visando favorecê-la e responder às novas demandas sociais. Por esses motivos, procurou-se investigar a cooperação e refletir sobre seu desenvolvimento dentro de uma organização curricular que privilegia a sua presença desde $o$ planejamento do curso estudado.

A escolha da Epistemologia Genética de Jean Piaget responde a essa necessidade, pois permite compreender o conceito de cooperação no processo de desenvolvimento cognitivo e de socialização do pensamento e como a experiência de cooperação promove a autonomia intelectual e moral dos sujeitos.

A pesquisa que embasa este artigo teve como premissa afirmar que a cooperação, como é definida por Piaget, se desenvolve nos processos de ensino e aprendizagem em grupo e buscou compreender como ela se expressa na educação a distância. A elaboração de Mapas de Trocas Intelectuais é um procedimento para a observação do desenvolvimento da cooperação no acompanhamento e na avaliação da aprendizagem e da construção de conhecimentos novos dos alunos pelo docente.

Ao procurarmos compreender como os processos individuais e interindividuais dos sujeitos possibilitam a ocorrência de cooperação em um curso na modalidade a distância, diferenciamos vários fatores imbricados neste processo, como o papel do docente, a concepção epistemológica de cada integrante, os processos avaliativos e coercitivos, as limitações dos participantes para trabalhos em grupo, a falta de autonomia, entre outros. Embora todos esses processos tenham sido considerados, manteve-se o foco nas sequências dos contatos que ocorreram entre os participantes e que foram registradas, com a definição de rotas e o desenho de Mapas de Trocas Intelectuais. Essas trocas escritas ocorreram em três fóruns selecionados para a busca e em três tempos distintos do curso: início, meio e fim. Os critérios de escolha desses fóruns levaram em consideração o fato de serem de docentes diferentes e de ofertarem propostas de atividades diversas. O primeiro deles envolvia uma atividade de discussão a partir de um tema, aliando-o às vivências pessoais e às experiências profissionais dos participantes; o segundo apresentava uma atividade mais específica, de trabalhar conteúdos; e o terceiro trazia uma proposição de integrar novidades com os conteúdos abordados. Optou-se por selecionar fóruns de um único tópico de discussão por permitirem um melhor mapeamento dos fatores que esta investigação pretende alcançar.

A pesquisa é qualitativa. Trata-se de um estudo de caso, conforme Yin (2010), realizado em uma turma de 50 alunos do curso de especialização e, para o tratamento dos dados, utilizou-se a Análise de Conteúdos de Bardin (1988). Os resultados encontrados, a partir dos estudos das trocas entre os participantes e do traçado das sequências das rotas, foram organizados na forma de diagramas representando os subgrupos de alunos que se constituíram nas trocas e o fluxo dos contatos entre eles. Depois, foi feito o desenho dos Mapas de Trocas Intelectuais, que se mostraram como representações profícuas para orientar a ação docente na educação a distância. 


\section{A cooperação em Piaget}

O conhecimento, para Piaget, é o resultado da interação sujeito-objeto, em continuidade à interação organismo-meio. É através de suas ações que o sujeito extrai informações sobre seu ambiente, as assimila e se acomoda ao novo.

Piaget (1977) afirma que a cooperação é indispensável para a elaboração racional, defendendo o trabalho em grupo nas práticas educacionais como parte do processo ativo do aprendente. Cumpre salientar que, com isso, o autor não elimina a diferenciação dos pontos de vista, isto é, não se trata de homogeneizar, mas de colocálos em reciprocidade.

A aprendizagem cooperativa é, de acordo com Piaget (1973), a forma de aprender a aprender por meio de atividades (ações e operações) - sejam estas interações com objetos físicos e culturais individuais ou coletivas. Assim, discentes e docentes, baseados em regras autônomas e no respeito mútuo entre todos que fazem parte do coletivo de aprendizagem, interagem para estabelecer trocas como as operações do tipo correspondência, complementaridade e/ou reciprocidade. A cooperação, então, é considerada como a coordenação do conjunto de trocas de ações e operações que os indivíduos realizam entre si quando desejam alcançar o mesmo objetivo.

Lembremos que colaboração e cooperação são termos comumente utilizados como sinônimos e expressam conceitos distintos para Piaget (1973), dentro de uma gênese $^{1}$. A colaboração é a união de ações que são realizadas de forma isolada pelos componentes de um grupo, mesmo que tenham um objetivo comum. A cooperação vai além, pois se encontra vinculada à interação, requerendo vínculos e reciprocidade afetiva entre os componentes do processo de construção de conhecimento. Essas interações possibilitam a mudança do sujeito em sua estrutura de conhecimento e do grupo como um todo, gerando novas possibilidades no sistema de interações. $O$ acréscimo de vários pontos de vista de forma coordenada modifica toda a estrutura, tanto no nível individual como no grupal, o que o autor denomina de Totalidade Social.

Assim, o equilíbrio nas trocas, entendido como o estado no qual os sujeitos se encontram de acordo, é alcançado através da conquista das condições de equilíbrio, que implicam um agrupamento lógico de proposições, isto é, a elaboração de um conjunto de regras que constitui uma regra formal, considerando-se que a troca de proposições, como conduta social, comporta a lógica dos sujeitos.

Piaget indica que, para que ocorra a cooperação, é necessário que três condições sejam preenchidas (Piaget, 1973, p. 108-109): 1) a existência de uma escala comum de valores intelectuais, que possam ser expressos através de símbolos comuns unívocos; 2) a conservação das escalas de valores, gerando obrigações para aqueles que as reconhecem; e 3) a atualização constante dos valores construídos, sem contradições de ambas as partes.

O autor afirma que essas três condições ocorrem somente nas trocas cooperativas, sendo que, no equilíbrio das trocas, visualizamos um sistema de normas, diferentemente das regulações simples. Essas normas expressam os agrupamentos operatórios, que são conceituados como um sistema de substituições possíveis, tanto individual, como de um indivíduo ao outro (cooperação) (Piaget, 1973).

Assim, tratando-se do sujeito e das suas relações com o meio físico (como sistema fechado), concebe-se o desenvolvimento da lógica como uma passagem progressiva da ação efetiva e irreversível à operação ou ação virtual e reversível. A

\footnotetext{
${ }^{1}$ Gênese: transformação de um estado para outro, comportando o sentido de uma evolução.
} 
lógica é uma forma de equilíbrio final das ações que parte da evolução sensório-motora e mental, requerendo a reversibilidade para o equilíbrio. $\mathrm{O}$ agrupamento é a estrutura que exprime esse equilíbrio (Piaget, 1973). O agrupamento resultante do equilíbrio das operações individuais e o agrupamento que exprime a troca mesma se constituem juntos e são as duas faces de uma única realidade. O mesmo ocorre quando o "eu" é substituído por "nós" e os sujeitos co-operam (operam juntos).

\section{Metodologia}

Como já antecipamos, trata-se de uma pesquisa qualitativa na forma de um estudo de caso, de acordo com Yin (2010), na qual se procurou compreender os processos individuais e interindividuais que participam do método de cooperação intelectual entre os discentes de uma turma de um curso de especialização em educação a distância na Universidade Federal do Rio Grande do Sul. Optou-se pela pesquisa qualitativa por ser uma abordagem que permite que ao pesquisador aprender o significado do que está intrínseco no fenômeno estudado.

Foram instrumentos da pesquisa as postagens efetuadas nos três fóruns selecionados e os registros dos materiais disponibilizados pelos docentes no ambiente virtual de aprendizagem, tais como textos, vídeos, atividades, interações, etc. Os materiais produzidos pelos discentes, como textos e postagens em outros fóruns, serviram de apoio para a compreensão do nosso problema. Identificaram-se as trocas intelectuais ocorridas entre os discentes nas disciplinas A ( $2^{\circ}$ disciplina do curso), B $\left(6^{\circ}\right.$ disciplina do curso), e $\mathrm{C}$ (última disciplina do curso). E, estudou-se o projeto pedagógico do curso e realizou-se acompanhamento sistemático do Moodle. Foram mapeadas as trocas que ocorreram nos fóruns selecionados entre os integrantes, buscando-se estabelecer aproximações e diferenciações entre elas.

Quanto ao público pesquisado, trata-se de uma turma de 50 alunos de um curso de especialização na modalidade a distância da universidade pelo período de dois semestres. A faixa etária varia entre 22 e 64 anos, sendo a maioria do gênero feminino e quase todos residentes de Porto Alegre ou cidades vizinhas. Os níveis de escolaridade e as formações são bastante diversos. Fazem parte deste grupo oito docentes, que foram responsáveis por ministrar as nove disciplinas do curso e orientar os trabalhos de monografias. A cooperação foi incluída na proposta curricular; como um componente do curso.

Foram tomados os devidos cuidados éticos na pesquisa, com solicitação de autorização do departamento e da coordenação do curso, a leitura e assinatura dos Termos de Consentimento Livre e Esclarecido dos Docentes e dos Discentes, e a identificação dos participantes foi preservada.

\section{Mapas das Trocas Intelectuais}

Para a compreensão do método da cooperação no curso identificou-se as trocas intelectuais ocorridas entre os discentes nas três disciplinas selecionadas; estudou-se o projeto pedagógico do curso; e realizou-se um acompanhamento sistemático do Moodle. Os fóruns são do tipo de discussão simples, e os dados foram coletados ao final do curso. O mapeamento das trocas que ocorreram nos fóruns selecionados entre os integrantes buscou estabelecer aproximações e diferenciações entre elas. 
Por trocas intelectuais entendem-se os atos comunicativos que advêm das trocas entre os participantes, que incluem a existência de regras de convívio, com a conservação de valores acordados entre eles, pois, de acordo com Piaget (1973, p. 109): "A discussão só é, pois, possível mediante as conservações, o que mostra de antemão o caráter normativo de toda troca de pensamento regulada por oposição às regulações de uma troca de ideias baseada em simples interesses momentâneos".

Assim buscou-se nos três fóruns identificar as trocas que ocorreram entre os participantes e registrar os movimentos que foram realizados nesses percursos, seguindo cada postagem e suas ligações subsequentes, constituindo, desta forma, as rotas. Desenha-se cada mapa a seguir, com o intuito de exemplificar o processo, com uma rota de cada fórum, com os seguintes critérios de seleção: um mínimo de quatro participantes e um mínimo de sete sequências nas quais houvesse trocas sobre algum tema específico. Esses critérios foram definidos por permitirem um acompanhamento mais sistemático e detalhado dos percursos das trocas efetuadas. $\mathrm{O}$ desenho de cada mapa foi elaborado a partir da sequência estabelecida através da rota das trocas de cada sujeito com os demais; para que fosse possível visualizar as interações que ocorreram.

Aqui, apresentamos uma rota para exemplificar como ocorreu esse processo de trocas intelectuais entre os sujeitos do primeiro fórum. A rota do fórum 1 segue a seguinte ordem de postagens: $39 \rightarrow 40 \rightarrow 41 \rightarrow 88 \rightarrow 99 \rightarrow 105 \rightarrow 111 \rightarrow 183 \rightarrow 189$ $\rightarrow 194 \rightarrow 229$. Essa ordem numérica segue a contagem das postagens realizadas e, que foram numeradas desde o início de cada fórum.

Nessa rota participam seis discentes (DI) e uma docente (DO), totalizando 12 postagens, das quais duas são da docente. Seu disparador foi uma postagem de material efetuada por um discente. A partir desta, seguiram-se interações nas quais se destaca, inicialmente, a discussão de pontos dos conteúdos disponibilizados. Essa rota iniciou-se com as postagens realizadas por DI 17, DI 9 e DI 20, respondendo a uma atividade proposta pela docente na qual solicitava que comentassem os textos estudados apresentando aspectos que considerassem inovadores. A rota segue com comentários de DI 42 sobre as três respostas anteriores sobre o tema, sucedidos pelas respostas a cada postagem.

Nesse fórum 1 destacaram-se elementos que foram sendo constituídos no início do curso, tais como a determinação de termos conceituais comuns, a definição do papel do psicopedagogo e as práticas inerentes a esta profissionalização, a busca de uma maior clareza dos termos científicos utilizados neste processo, entre outros.

Aqui, se impõe a necessidade de que os sujeitos conservem o que foi reconhecido como válido previamente para que não ocorram contradições a fim de permitir a continuidade das trocas intelectuais. Desta forma, o cumprimento dos acordos é parte inerente ao processo.

Assim, para que o processo de trocas intelectuais tenha andamento, as proposições acordadas devem ser lembradas, e as mediações tanto propositivas, quanto argumentativas por parte do docente, de outro colega ou mesmo do próprio sujeito, ao descentrar-se no processo de ensino-aprendizagem, tornam-se, desta forma, atos comunicativos, componentes e aliados frutíferos para a continuidade das trocas. Desta maneira, parte-se do princípio de que a não contradição, que é um princípio lógico do método da cooperação, é um requisito para a conservação de acordos, coordenando as diferentes perspectivas, e espera-se que os sujeitos cumpram o acordado.

Por meio deste mapeamento, apresenta-se um exemplo de registro de dois discentes (DI 44 e DI 1) que procuravam precisar o significado de termos utilizados no curso: 
DI 44: [...] Obs: Como disse em depoimento anterior, estou aprendendo com o curso. A minha experiência em sala de aula foi há 12 anos com o EJA e estágios realizados durante o curso do magistério. Se me equivoquei com alguma teoria, peço que me corrijam.

DI 1 [...] Logo, vi sim muitos termos diferentes e inovadores como hiperpassividade relacionando com a hiperatividade, onde se trata sobre a passividade dos alunos, na qual também devemos estar de olho, pois, isso também pode dificultar os processos de aprendizagem dos alunos.

A partir dessa rota, desenhou-se o seguinte Mapa das Trocas Intelectuais. Os círculos representam os sujeitos (discentes e docentes) conforme o código estabelecido, e as setas indicam a postagem e as direções nas quais ocorreram.

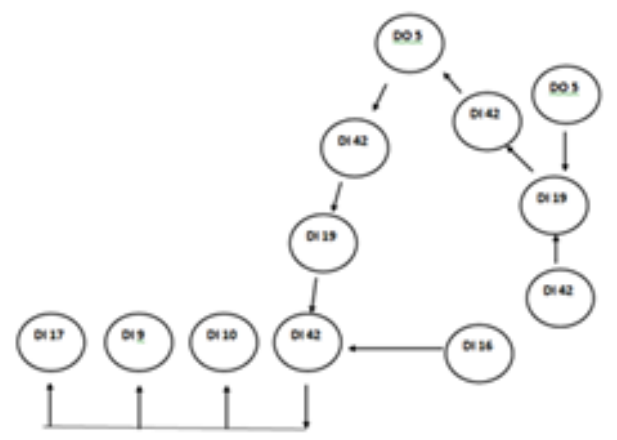

MAPA 1 - Rota do fórum 1

Nesta rota, é possível perceber que a maior parte das interações centraliza-se na conduta do sujeito DI 42, que é alicerçada em um tema de interesse comum aos participantes.

Neste fórum é que os integrantes buscaram constituir escalas de valores a serem compartilhadas no grupo. Como era o fórum inicial do curso, essa necessidade de construção da identidade do grupo, de um sentimento de pertencimento, mostrou-se como uma parte importante, que deve ser considerada na proposta do curso a fim de promover esses fatores e viabilizar esse processo. Piaget (1998) refere que a cooperação requer vínculos e reciprocidade afetiva entre os componentes, sendo que, desta forma, o cuidado com a construção de uma identidade grupal torna-se um dos elementos necessários ao método de cooperação. Neste sentido, os temas afins e as experiências pessoais e profissionais mostraram-se facilitadores, possibilitando o acréscimo de pontos de vista diversos e a descentração, o que, de acordo com Piaget (1973), modifica toda a estrutura, tanto no nível individual, quanto grupal.

A cooperação, neste momento, se expressou como construção de uma linguagem comum, de clareza dos conceitos científicos, nos termos utilizados pelos participantes, o que se interpreta como componentes importantes do método de cooperação. Além destes, a constituição de escalas de valores entre os participantes são importantes e ocorrem com a finalidade de balizar as relações.

A seguir, exibimos uma rota do Fórum 2, traçada para a observação de trocas intelectuais efetuadas pelos sujeitos neste espaço. Esta segue a seguinte ordem numérica, de acordo com as postagens realizadas: $69 \rightarrow 73 \rightarrow 74 \rightarrow 84 \rightarrow 123 \rightarrow 124$ $\rightarrow 129 \rightarrow 130$. Esta rota se inicia a partir de uma postagem de material efetuada por um discente, sobre a temática de Metodologia de Projetos de Aprendizagem. Nela participam três discentes e uma docente, num total de oito postagens, uma sendo da docente.

No mapa a seguir, expõe-se essa rota do Fórum 2 para visualização das trocas efetuadas. DI 13 inicia a rota com a postagem de sua atividade, debatendo o tema 
proposto. A partir daí, DO 7 realiza um feedback positivo desta postagem. Outra discente, DI 14, dirige-se diretamente a DI 13, agradecendo por suas contribuições, referindo que lhe foram valiosas. DI 42 entra no diálogo dirigindo-se diretamente a DI 13, identificando-se com o discurso da colega e citando a sua experiência pessoal, que corrobora o que foi postado. Com isto, DI 13 retoma e estabelece o elo mostrando uma identificação mútua e continuando o diálogo.

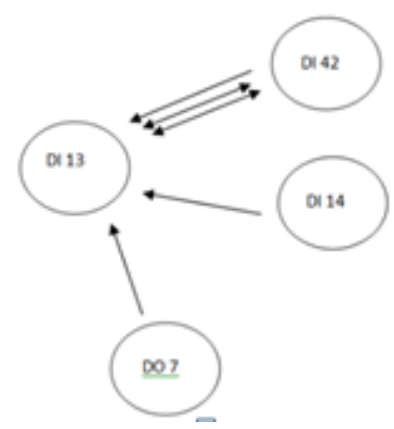

MAPA 2 - Rota do fórum 2

O que se visualiza nesta rota é que há uma díade que assume a conversação e se mantém pela identificação de concepções e práticas comuns entre os dois sujeitos - ou seja, fundamenta-se em interesses afins. Outro fato que se pode perceber é que os comentários, quando são seguidos de perguntas acarretam a exigência de uma resposta do interlocutor. Neste momento, observou-se a cooperação como trocas intelectuais nas cobranças de acordos entre os participantes, adequando e reequilibrando as escalas de valores. Os sujeitos confrontam suas ideias, proposições, concepções, valores, e esse processo requer uma constante reequilibração.

O respeito mútuo, elemento da mudança das relações heterônomas para as relações autônomas é um dos pontos que merecem destaque nesse processo. O respeito mútuo pode ser visualizado no relato a seguir, onde as colegas identificam-se a partir de práticas profissionais semelhantes, reconhecendo o valor do trabalho de cada uma.

F 1 - P 55: DI 18 : Querida colega DI 44! Adorei ler o relato que fizeste sobre tua experiência na X e reconhecer o quanto tuas práticas realmente possibilitaram aos educandos a manifestação de uma corporeidade reprimida, desacreditada. Como educadora de jovens e adultos, também busquei romper com esses estigmas e senti maior facilidade de fazer isso durante o meu trabalho no $x$, que não era um espaço institucional, embora a turma se reunisse em uma escola. [...]

Assim, considerou-se que este fórum promoveu descentrações que implicaram condições para que os sujeitos conseguissem deslocar-se de seus pensamentos egocêntricos, comparando-os com os dos colegas, incluindo o ponto de vista singular no coletivo, contemplando, assim, relações de reciprocidade.

Observa-se também, que foi o momento do curso no qual ocorreu um número maior de conflitos, de cobranças de acordos entre os integrantes e credita-se a este ponto a necessidade de adequação, de reequilíbrio das escalas de valores. Ou seja, analisa-se que os sujeitos, ao realizarem trocas intelectuais, confrontam suas ideias, proposições, concepções, valores e esse processo, requer uma constante reequilibração. Sabe-se, como afirma Piaget (1976), que o equilíbrio nunca é um equilíbrio estático, sempre se trata de um equilíbrio dinâmico, portanto, uma equilibração.

Desta forma, considera-se que as trocas efetuadas neste espaço que se alicerçaram, principalmente, em aportes teóricos que atuaram como propulsores de outras perspectivas, através de atos comunicativos entre os participantes, da elaboração de um 
código linguístico comum, de conhecimentos compartilhados, da instituição e manutenção equilibrada de acordos comportam a descentração e a construção de novos conhecimentos científicos.

Por último, apresenta-se uma rota do Fórum 3, visando a compreensão das trocas ocorridas entre os participantes ao final do curso. A ordem numérica das postagens é: 15 $\rightarrow 19 \rightarrow 20 \rightarrow 35 \rightarrow 36 \rightarrow 37 \rightarrow 39 \rightarrow 41 \rightarrow 42 \rightarrow 44 \rightarrow 66 \rightarrow 67 \rightarrow 68 \rightarrow 76 \rightarrow 77$ $\rightarrow 78 \rightarrow 79$.

Nesta rota participam cinco discentes, e ela inicia com uma postagem de uma notícia de interesse comum que atua como disparador das trocas. Foi criada uma rota com 17 postagens, sem participação de docente.

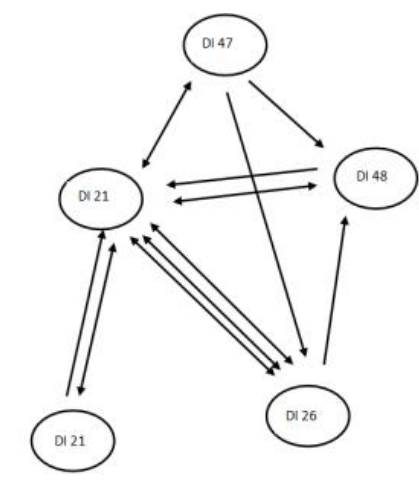

Mapa 3 - Rota 1 do fórum 3

Aqui, novamente a convocação para as trocas parte de um material disponibilizado que aborda interesses partilhados pelos sujeitos. Também se observa que o sujeito DI 22 coordena o debate, trocando ideias com os demais e mantendo o foco no assunto em questão. Formou-se um grupo pequeno, mas mais coeso. Além disso, também se visualiza que as perguntas supõem uma reciprocidade, ou seja, há a expectativa de resposta, de trocas como ocorre, por exemplo, nestas postagens:

F 3 - P 10: DI 21

[...] O texto que escolhi retrata a situação que presencio diariamente nas escolas em que atuo. $O$ laboratório de informática na maioria das vezes é uma ilha dentro da escola, onde se passa um tempo com os alunos. [...] Apesar de muitos avanços é preciso traçar caminhos para que os professores possam fazer uso das novas tecnologias com qualidade, ou seja, é preciso também novas posturas por parte dos professores para que se tenha êxito.

F 3 - P 12: DI 16

DI 21 no teu texto há a grande chave de muitas discussões durante o curso: a falta de formações e infraestrutura nas escolas que permitam a utilização eficaz das Tics. O ambiente virtual nos disponibiliza muitas informações, mas ainda temos dificuldade nas escolas de transformar tanta informação em conhecimento. Será essa a dificuldade da educação nos dias de hoje?

Neste último fórum do curso, observou-se que a cooperação entre os participantes ocorreu com trocas intelectuais equilibradas, sem conflitos, com uma integração em prol do objetivo final desejado por todos: o término do curso. Parte-se do pressuposto de que as trocas entre os participantes estavam equilibradas, uma vez que neste fórum e neste momento final do curso, não demonstraram haver maiores conflitos. Cumpre esclarecer que não se parte do princípio de que a ausência de conflitos equivalha à manutenção do equilíbrio e dos valores acordados, mas, que, neste momento, não foram detectados conflitos de qualquer ordem que pudessem servir de indicativo de desequilíbrio neste sistema. 


\section{Considerações Finais}

O que se estabeleceu como foco central neste artigo foi investigar como os processos individuais e interindividuais possibilitam o desenvolvimento da cooperação intelectual entre os discentes no contexto de um curso de especialização na educação a distância.

Partiu-se do pressuposto de que as diversas interações, nas várias ferramentas constituídas no Moodle, como fóruns, chats, wikis e outros, podem subsidiar a cooperação intelectual nos processos de ensino e aprendizagem. Desta forma, o desenvolvimento do sujeito, entendido como um processo individual é visto como fundamental para a ocorrência de cooperação. O sujeito só poderá operar em comum, a partir de condições de desenvolvimento individual que lhe permitam se descentrar do seu ponto de vista para estabelecer relações e atuar em reciprocidade em processos interindividuais, possibilitando a cooperação. A atividade operatória interna, suas coordenações e a cooperação com os outros são aspectos complementares de um único conjunto, equilibrando-se mutuamente.

Procurou-se investigar como ocorrem as trocas intelectuais, como elas se constituem e como são construídas em busca de observáveis, considerados como: "aquilo que a experiência permite constatar por uma leitura imediata dos fatos por si mesmo evidentes" (Piaget, 1976, p. 46). Neste caso, há, por exemplo, um código, a língua portuguesa, que é compartilhado por todos, com um sistema de noções definidas, sendo que as definições podem convergir inteiramente ou divergir parcialmente, mas ele constitui uma mesma chave que permite aos sujeitos traduzir suas noções no sistema do outro.

Os resultados alcançados esclarecem fatores que podem predispor e fomentar ou inibir as relações de cooperação. Considera-se que fatores como o interesse e a autonomia dos sujeitos, o design do curso, os diferentes tipos de mediação do docente, a constituição de espaços que possibilitem a comunicação entre todos e as atividades que são promovidas devem ser considerados como componentes de um processo de ensino e aprendizagem promotor de cooperação intelectual. Além disso, a identificação com o tema é um gerador significativo para as interlocuções entre os participantes, como fica demonstrado nos mapas. Outros indicadores que observamos foram as afinidades entre os sujeitos, seja por vivências pessoais semelhantes, práticas afins, ambientes de trabalho similares, entre outros.

Apresenta-se a coação que determinado sujeito exerce sobre outro como um dos fatores que se identificados como inibidores do processo. Esse elemento não se refere somente ao papel do docente, mas também é encontrado entre discentes, no sentido de sentir-se inferiorizado adiante do outro e isto inibiu a participação frente ao grupo. A presença de um docente centralizador também influencia negativamente o processo de trocas entre os participantes. A ausência de espaços e tempos que propiciem movimentos de trocas, bem como atividades singulares inibe os participantes de cooperarem. Outros fatores são os desequilíbrios de conhecimentos prévios e as intervenções nomeadas e realizadas com o intuito de cobrança por parte de docentes.

Nas rotas traçadas para representar as trocas intelectuais, há várias interlocuções que se cruzam, nas quais um discente responde ao outro, sem que tenha sido este que foi interpelado, relançando e mantendo a continuidade do processo. As trocas, desta forma, mantêm o processo de aprendizagem através das relações entre os participantes no ambiente virtual de aprendizagem. 
Esses fatores são apontados como constituintes para a ocorrência ou não do método de cooperação entre os discentes no curso. Não se observou hierarquia entre esses fatores, mas pode-se considerar que, em determinados momentos, algum destes pode ter tido uma importância maior, tanto positivamente quanto negativamente, para favorecer determinadas ações ou reações ou para inibi-las. Considera-se que nos vários momentos do curso, os fatores citados de cada fórum, equivalendo a cada momento do curso, tiveram destaques diferenciados, o que não configura uma hierarquia, mas destaca elementos que devem ser contemplados no planejamento de cursos na modalidade a distância.

O acompanhamento através do mapeamento das rotas facilita a identificação dos interesses dos discentes, os temas que os motivam, as dificuldades que podem estar enfrentando e as possibilidades de novos encaminhamentos, tais como a clareza dos termos conceituais do curso, a definição do papel profissional e as práticas inerentes à profissão. Enfim, acredita-se que, com o traçado dos Mapas de trocas intelectuais, podese, inclusive, averiguar possíveis desequilíbrios nas escalas de valores e a ausência de reciprocidades, que são fatores fundamentais à cooperação na $\mathrm{EaD}$.

Destaca-se, a partir dos resultados da pesquisa, a importância da cooperação no processo de ensino e aprendizagem, pois possibilita a ocorrência de trocas intelectuais em constante reequilibração, isto é, visando a equilibração majorante, um equilíbrio com melhoramento. Desta forma, o estabelecimento de relações cooperativas pode propiciar enriquecimento mútuo para todos os participantes.

Acredita-se que o uso dos Mapas de Trocas Intelectuais, compreendidos como instrumentos auxiliares para a leitura das interações ocorridas no AVA, permite, a partir de sua interpretação baseada na contribuição de Piaget, que os docentes elaborem planejamentos mais eficazes de suas práticas e acompanhamentos que possam promover e intensificar as trocas intelectuais entre os participantes, fomentando as relações de cooperação no grupo e, consequentemente, qualificando a educação.

\section{Referências}

BARDIN, L. Análise de Conteúdo. Lisboa: Edições 70, 1988.

CORBELLINI, S. A cooperação intelectual entre discentes na Educação Online: um método em ação. 220 f. Tese (Doutorado em Educação). Universidade Federal do Rio Grande do Sul, Faculdade de Educação, Porto Alegre, 2015.

CAMPOS, F. A. et al. Cooperação e aprendizagem on-line. Rio de Janeiro: DP\&A,

PIAGET, J. Estudos sociológicos. São Paulo: Companhia Editora Forense, 1973.

PIAGET, J. A equilibração das estruturas cognitivas. Rio de Janeiro: Zahar, 1976.

PIAGET, J. O julgamento moral na criança. São Paulo: Editora Mestre Jou, 1977.

PIAGET, J. Sobre a pedagogia. São Paulo: Casa do Psicólogo, 1998.

YIN, R. K. Estudo de caso: planejamento e métodos. $4^{\circ}$ Ed. Porto Alegre: Bookman, 2010. 